\title{
Presenting Women as Sexual Objects in Marketing Communications: Perspective of Morality, Ethics and Religion
}

\author{
Md. Mahmudul Alam * \\ School of Economics, Finance \& Banking \\ Universiti Utara Malaysia \\ Sintok, Kedah, Malaysia \\ Email: rony000@gmail.com \\ Ahmed Aliyu \\ Sociology Department, Faculty of Arts and Social Sciences \\ Federal University Dutse \\ Dutse, Jigawa State, Nigeria \\ E-mail: ahmedaliyu2007@yahoo.com \\ Shawon Muhammad Shahriar \\ Institute for Environment and Development \\ National University of Malaysia \\ Bangi, Selangor, Malaysia \\ E-mail: shawon.shahriar@gmail.com \\ * Corresponding author
}

\section{Citation Reference:}

Alam, M.M., Aliyu, A., \& Shahriar, S.M. (2019). Presenting Women as Sexual Objects in Marketing Communications: Perspective of Morality, Ethics and Religion. Journal of Islamic Marketing, 10(3), 911-927. (online) https://doi.org/10.1108/JIMA-03-2017-0032

This is a pre-publication copy.

The published article is copyrighted by the publisher of the journal. 


\title{
Presenting Women as Sexual Objects in Marketing Communications: Perspective of Morality, Ethics and Religion
}

\begin{abstract}
Purpose: In the current information age, when the attention spans of most people have become very short, marketers are facings serious challenges to grab the attention of their target audience effectively and fruitfully. From street corner to bedroom, virtually every perceivable location of human traces are littered with activity of marketers, whether they are small or large in scale, or the recipients of their information understand the message properly or not. Studying consumers' acceptance of the main ethical issues in communication, mainly in advertising has recently been receiving much attention from scholars. Therefore, in order to grab the attention of people in the increasing competitive environment, advertisers have resorted to using what they feel can quickly attract the audience. For example, the attachment of attractive women with their physical natural endowments presented in explicit sexually appealing postures to products/services that have no linkage with women. These practices have raised some moral and ethical questions within the society. Therefore, the scope of this study focuses on discussing marketing communication through presenting women as a sexual object from the morality, ethics, and religious perspectives.

Design/methodology/approach: This is a descriptive study based on the systematic literature review. Initially, this paper discusses the ethical issues of using women and sexual appeals in the process of marketing communication as well as the current level of practices in the industry. Then, it discusses the consequences and dimensions of the issues from different types of ethical grounds. Finally, it provides recommendations with the objective of finding a common ground from business and social perspectives. It also mentions the scopes of further research, which could lead the secular world to modify their moral values and come closer to the norms of other civilized societies.

Findings: The position of the paper takes is that considering the negative effects of the prevalent advertising in society, the practice falls short of human moral values; as a result, it is considered unethical.

Originality/value: This review paper examines the ethical implication of using women as marketing tools from the perspectives of morality, business, and Islamic principles that will help business groups as well as the whole religious community, especially Muslims.
\end{abstract}

Key words: Business ethics; Islamic business ethics; marketing ethics; media ethics; sexuality; feminism; Muslim

\section{Introduction}

Sharing of information is part and parcel of marketing communication, and the marketers communicate to the customers regarding the products, services or concepts on offer through mass media, direct communication and other conventional/non-conventional means. The main concern of the marketers and their clients is to promote the intended message or perceived benefits to the target audience regardless of the actual benefits of the products or services. Media outlets oftentimes turn a blind eye to these dubious marketing activities for the sake of their own sustenance. Although high percentage of the business community are benefiting from these activities directly, the minds of the innocent people get programmed through them, and they subconsciously become affected by them. 
Sexual appeal is an indispensable biological instinct of the humans. Marketers naturally have a tendency to capitalize on this weak point of the human mind. From the perspectives of marketers, "advertisements that attract attention have the increased likelihood to affect persuasion" of the target audience (Taflinger, 1996). The concept of "sex sells" is the outcome of this marketing perspective, leading to normalize the sexual imagery in the minds of people, and the imagery was once considered pornographic. The effects of the concept of "sex sells" can now be seen on primetime television programs, on the pages of well-known magazines, on billboards, websites and other means of marketing activities.

According to some research findings, sexual appeal may serve several roles in the context of marketing activities (Vezich, Gunter, \& Lieberman, 2017; Dahlen \& Rosengren, 2016; Taylor, Miyazaki, \& Mogensen, 2013; Huang \& Lowry, 2011; Schiffman, Wisenblit, \& Kanuk, 2010; O'Guinn, Allen \& Semenik, 2009; Levy, 2008; Sherman \& Quester, 2005; Orth \& Holancova, 2003). Firstly, these contents generally tempt people, so they have the "stopping power". Secondly, they arouse the emotional faculties of people, and make the message memorable and easy to relate. Thirdly, these advertisements provoke a desire to consume the products or services advertised. Some brands have even claimed that by utilizing the sexual appeal, they sell their products more; thus, they help generate more employment and benefit the overall society. For such brands and many others, sexual appeal is central to their brand positioning. Reichert et al. (2001) argue that advertisements, which include sexual images create more "positive feelings" in the minds of their target audience than advertisements that do not include them. They also claim that advertisements that include sexual images are more engaging, encompassing, and interesting than those that do not include them (Bryła \& Gruczyńska, 2018; Ashraf, Amin \& Ahmad, 2015). Walker (1999) argues that sexual appeal and nudity grab attention of people regardless of their age, gender or cultural background. Sexual images have high attention values, which arouse the immediate attention of both men and women. Moreover, Bushman (2005) claims that a large number of individuals pay more attention to sexually explicit media contents than the nonsexual contents.

Nevertheless, sexually explicit advertisements may backfire on some occasions as well, especially when a female body is utilized in a "humiliating or insulting way". Consequently, these advertisements may have a negative effect upon the brand advertised itself. For a long time, many researchers have argued that after getting exposure to a sexually explicit advertisement, many viewers are likely to direct their attention to the sexual stimuli instead of paying attention to the message and other cues in the advertisement; thus, the exposure negatively affects the brand recall of these consumers (Vezich, Gunter \& Lieberman, 2017; Waller \& Fam, 2015; Bushman, 2005; Bushman \& Bonacci, 2002; Latour \& Henthorne, 1994; Alexander and Judd, 1978; Steadman, 1969). Furthermore, Taflinger (1996) argues that inappropriate application of sex symbols may even drive away some conscious consumers from watching the advertisement at all.

Beyond the arguments of the positive or negative impacts of using sexually explicit contents and female bodies in marketing activities and approaches, ethical issues and norms should also be incorporated strongly in the discourse. Some organizations start using and practicing the ethical message in advertising to reach their target customers successfully. However, at the same time, unethical advertising has been realized as a large element that some firms use intentionally or unintentionally to mislead consumers in the sale of unnecessary products/services (Ogechukwu, Ndubueze \& Uche, 2011; Harker, 2008; Boddewyn \& Kunz, 1991). Although ethics is supposed to play an important role in the 
marketing community, what is lacking now is a clear code of conduct for the marketing professionals and media outlets that will be acceptable to all relevant stakeholders. Therefore, by covering a wide range of papers, this study follows a systematic literature review to focus on the topic of the paper. Based on the literature review, this paper discusses the issues of ethics of using women and sexual appeals in the process of marketing activities with the objective of finding a common ground from business and social perspectives.

\section{Current Scenario of the Industry}

Sexuality used to be associated with disgrace and guilt until the advent of the twentieth century. However, the scenario changed during the last century when marketers started relying heavily on female bodies and sexually explicit contents. Over last several decades, women are increasingly being portrayed as counterparts of men. Consequently, according to Atkin and Miller (1975), children who were exposed to these advertisements consider male dominated roles more appropriate for females than their traditional homemaking role. Additionally, children are now exposed to inappropriate contents due to the pervasive presence of scantily clad or semi-nude women posing as decorative objects in many advertisements.

The current consumer culture, where the body is celebrated as a site of pleasure, is also contributing to this phenomenon of using women as sex objects in advertisements and other promotional activities. This culture allows advertisers to touch the borderlines of the "forbidden" to grab people's attention (Meade \& Zhou, 2017; Thiyagarajan, Shanthi \& Naresh, 2012; Liu, Cheng \& Li, 2009; Jones \& Reid, 2009; Pope, Voges \& Brown, 2004; Lambiase \& Reichert, 2003; Reichert, Heckler, \& Jackson, 2001; Heckler \& Jackson, 2001; Treise et al., 1994; Bello, Pitts, \& Etzel, 1983; Reid \& Soley, 1983; Reid \& Soley, 1981). Moreover, the edges of these "acceptable limits" are pushed all the time. It is quite safe to assert that many of the sexually explicit advertisements nowadays would have been considered as pornography a hundred years ago. Among the several elements, visual element with "attractive" models is the most common in sexually explicit advertisements. Lambiase and Reichert (2003) state that generally sexually explicit advertisements contain five types of information, which are nudity, sexual behaviour, physical attractiveness, sexual innuendos, and sexual embeds. Pingree, Hawkins, Butler, and Paisley (1976) measured the scale of sexism in advertisement by ranking the sexist depiction of women from the lowest level of sexism to the highest level. Similarly, Goffman (1979) portrayed women in advertisement in three categories such as, submissive, objectified, and sexist.

Moreover, the perception of people regarding nudity and sexually explicit contents differ considerably depending on the respective cultures and traditions. The study of Lambiase and Reichert (2003) reveals that nudity in advertisements is referred to short skirts, tight tops, muscular arms, bikinis, and lingeries. Moreover, advertisements have exaggerated nudity offensively and focused more on the execution technique (e.g., nudity) compared to the products per se, such as advertisements of underwear (Waller \& Fam, 2015; Parry et al., 2013; Putrevu \& Swimberghek, 2013; Ting \& De Run, 2012; Waller, 2007). Furthermore, most of the cases, the issue of sexism is used in the ad when it has no logical relationship with the advertised product, and this is considered as incongruity. As a result, there is no logical argument for using nude or sexually exposed women in car advertisement (Yoon, 2013; Orth \& Holancova, 2003; Sherman \& Quester, 2005). 
A study by Baker (2005) shows that an average person in the USA is exposed to over 3,000 advertisements each day and many of the advertisements portray women as sex objects. Though in advertising, people do not consider the term sexual nudity in women literally it refers to any suggestive dress that is often represented by open blouses with partially exposed cleavage and tight fitting clothing that highlights the feminine body. Appearance of completely nude models is very rare in mainstream advertisements; however, sexual sensation in people is sometimes aroused by side and back shots of the models, shower scenes and frontal nudity from the waist up. Moreover, although the acts of sex themselves are not portrayed directly in mainstream advertisements, on many occasions, provocative behaviour is shown to give sexual clues. Furthermore, sexual appeal as humour is also widely used in advertisement (Groza \& Cuesta, 2011; Jones \& Reid, 2009; Ford, Boxer, Armstrong \& Edel, 2007).

Besides advertisements, some retail outlets are utilizing the female body to attract more customers through revealing and provocative attires of their salesgirls and waitresses. The contemporary consumerist capitalist society now appears to be fascinated with the use of female bodies and sexually explicit contents that in many societies have been integrated as an integral cultural component of that society, or at least of a quarter of that society.

\section{Consequences of 'Sex Sells' Marketing}

The phenomenon of feminism has been on rise since the First World War. The effects of the rise of the phenomenon of feminism can be felt in many facets of the society, including the attitude toward female body exposure and sexuality. In many contemporary cultures, sexual objectification of women is considered as a form of women empowerment. With the passage of time, this "liberal" attitude is becoming the norm in many societies, and the attitude was considered conservative previously.

This pervasive change in social norms is changing the thought process among children and the young in particular with regard to their attitude to women and the female body. Some researchers have associated repeated exposure to sexually explicit media contents with a broad range of social problems, such as sexist attitudes and beliefs, sexual harassment, violence against women, eating disorders, and stereotyped perceptions of and behaviour toward men and women (Zell, Strickhouser, Lane, \& Teeter, 2016; Milakovic \& Mihic, 2015; Pradhan, Duraipandian \& Sethi, 2014; Huang \& Lowry, 2011; Rouner, Slater \& Domenech-Rodriguez, 2003; Schiffman, Wisenblit, \& Kanuk, 2010; Orth \& Holancova, 2003; Lee, Harrell, \& Droge, 2000; Beckwith, 1994; Fredrickson \& Roberts, 1997). Critics also point out that the sexist advertisements create an unrealistic standard of female body in the minds of men and women. These advertisements and media activities are also associated with some broader psychosocial constructs, such as lower self-esteem, lower life satisfaction, lower relationship satisfaction, risk-taking instinct, self-harm, and negative attitude toward breastfeeding (Breines, Crocker, \& Garcia, 2008; Harper \& Tiggemann, 2008; Mercurio \& Landry, 2008; Moradi \& Huang, 2008).

Some researchers have suggested a connection between exposure to sexually-oriented stimuli and aggression against women (Allen, D'Allesio \& Brezgel 1995; Emmers, Allen \& Gebhardt, 1995; Lanis \& Covell, 1995). Inclinations to rape and interpersonal violence against women have also been associated with these contents. Stern and Handel (2001) suggests that exposure to sexual scenes may lead young individuals to have sexual relations. Brown (2002) suggests that the exposure also increases acceptance of non-marital sexual 
behaviour among older adolescents. The exposure also leads to "unusual sexual behaviours", less expectation of sexual exclusivity with a single partner, lack of care about sexual abuse of children, and a lower concern about sexual activities that may lead to health risks (Zillmann, 2000). Consequently, exposure to these explicit materials may lead adolescents to consider the institution of marriage as sexually confining and the responsibility of child rearing as unattractive. Considering all these effects of "sex sells" marketing, it can be hypothesized that the marketing of 'sex sells' contributes to the rising trend of rape globally. In the USA alone, a woman is reported to have been raped in every 2 minutes, and 1 out of every 6 women has experienced rape and/or physical assault in their lifetime (RAINN, 2014). In addition, one third of teens become pregnant by the age of twenty in the USA, and this is a higher rate in comparison with other industrial nations (The National Campaign, 2014).

Moreover, these negative developments in media and culture are pushing many women into identity crisis. Advertising, celebrity culture and other multiple layers of media exposure are blamed for this phenomenon. The continuous exposures to these materials have lead many people, young people in particular to treat these things as ordinary and customary. Some of these people have also taken the models or "brand ambassadors" in these advertisements as role models and idols and they try to imitate their looks, outfit selection and style. Women are psychologically pushed to look, dress, appear and act in a certain way, which contributes to the physical, emotional and mental challenges that they face Although these activities take place in the guise of promoting of the latest lifestyle and trends, the stress level that many celebrities often go through is seldom mentioned.

Advertisers have used sex to sell every type of products and services imaginable. Strasburger and Wilson (2002) have shown that women are exposed to over 14,000 sexual references, innuendos, and behaviours in a year, but they are exposed to only 170 advertisements a year, and the advertisements involve the use of birth control, self control, abstinence, or responsibility. Many feminists have disapproval of this trend, arguing that the prevalence of sexually explicit contents in media harms opportunity for equal rights of women, encourages sexual aggression against them, degrades feminine role in the society, and confines them from the full exercise of their citizenship and participation in public life (Baker, 2005; Richmond \&Hartman, 1982; Van Zoonen, 1994). Based on the above account, many social science theorists may argue that continuous exposure to these contents and imagery may gradually condition the members of a society to find these items not so offensive and more acceptable transcending the demographic divides (Bandura, 1977; Ryan \& David, 2003). If this holds true, ethical issues should be brought forward strongly in order to examine these advisements' and media contents' abilities to shape moral values and cultural norms. It has also been argued that young and educated women, who once have found sexually explicit media contents as offensive, are now taking them casually and accepting sexual objectification of their gender.

\section{The Ethical Border}

\section{Perspectives of Morality}

All human societies are governed or regulated by norms, which specify the accepted standard of behaviour from each member of a particular group. Although certain norms have been institutionalized in accordance with modern civilizations, others are still kept and practiced as moral guides to standard behaviours based on shared values. Thus, while certain unacceptable behaviours are still regulated through societal moral codes for routine interaction, such as 
mode of dressing, courtesy and respect for elders and showing sympathy for women and children, others are controlled through legal and professional codes of conduct, which are known as professional ethics. Therefore, professional ethics, like societal moral codes are also the dos and don'ts established by recognised professions, such as law, medicine, marketing and advertising practitioners for their members. Paul and Elder (2006) defined ethics as 'a set of concepts and principles that guide us in determining what behaviour helps or harms sentient creatures'. However, it is imperative to understand that certain acts may be legally sanctioned, but they are yet unethical. An example is advertising marketing, which is aimed at attracting potential buyers without considering gender issues though men and women are different in terms of moral and ethical beliefs, values, and behaviour (Bryła \& Gruczyńska, 2018; Bruce, 2015; Cohen et al., 1998; Dawson, 1997; Ameen et al., 1996; Beutel \& Marini, 1995; Arlow, 1991; Peterson et al., 1991).

The emergence of target marketing, which is done through spontaneous dissemination of commercial messages to attract potential patronage from the public, over the recent years, has generated contentious discussions, revolving around ethical issues, such as moral and social values of the society. The impact of products advertisement on people in this era of globalization is not limited to acceptance and rejection issues rather it has permeated the overall conduct of the people, including self-perception, mode of dressing, eating habit, etc. Therefore, considering the pervasive influence of advertisement in public life, it has become important to ensure that advertisers, especially the mass media are conducting their business in accordance with established societal moral codes in their effort to attract potential customers for their clients.

This is because mass media as the avenues that help advertising practitioners reach their target audiences have come under serious criticism from both the academia and general public as a result of their inability to check the immoral contents of advertisement messages before disseminating them to the public. The most disturbing aspects of such offensive advertisements are those that revolve around depicting women with implicit sexual desirability. Thus, critics, especially feminists are of the views that continuous dissemination and display of advertising messages with sexual contents by the media is an indirect way of sanctioning the exploitation of women for commercial gains.

Fredrickson and Roberts (1997) in their 'Theory of Objectification' asserted that women were largely objectified as sex symbols and considered as material possessions which could be used by not only by one person but by many. Sexual objectification of women arises when certain part(s) of a particular female body is specifically identified and treated separately from the rest of the body as a person in order to present her sexually desirability by men. Furthermore, recent developments indicate that the majority of women seem to have accepted their labelling as such and have equally begun to reflect this notion in their physical appearances. For example, in their attempt to live according to the labels, some women have taken arbitrary use of drugs and questionable dieting in order to maintain or look sexually attractive to men.

Researches indicate that most television advertisements are particularly designed to cater to feminine features along racial origins. For instance, while women with African lineage are continuously portrayed as undomesticated and sexually aggressive (Greene, 1994), women with Asian background are presented as domestic ideals, such as sexually obedient, family oriented, highly cultured, etc. (Root, 1995). 
Prior to the globalization of the world, traditional marketing communications used to be sensitive to sociocultural issues and patterned their messages with moral sense of responsibility. This is because that they were aware that business managers should tailor their commercial activities along people oriented perspectives. Unfortunately, current development of marketing trend indicates that modern business promoters are only interested in making fortunes with recourse to public interest. Although in some cases marketing, personnel try to respond to sociocultural dictates based on geographical borders, the concept of global village due to information technology makes the distinction very difficult. Therefore, the issue of moral consideration must be a holistic approach from the general organizational mission instead of considering it in accordance with the dictate of profit and loss principles.

\section{Perspectives of Business Ethics}

Apart from functioning as the fourth realm of the society, the media can also be seen as business entities, especially following the downsizing/dwarfing of public media by the private ones. This is perhaps the reason that in spite of public criticisms, mass media have continued to disseminate sexual and violent messages with complete disregard of its potential effect on the society. Therefore, using women as marketing object can be understood from the business motives of both the media and advertisers. This is predicated to the fact that presentation of women seductively sometimes has no direct linkage with object that is advertised, and it is done primarily to attract more audience, and viewers as the medium and basis work advertisers to be charged. For example, many mass media contents, such as advertisements, entertainment shows, soap operas, movies are filled with seductive pictures of women in different postures because they are considered as sexual symbols that can easily attract the attention of men.

Taking the classical perspective into consideration, one can understand the rationale why women are used by the mass media as marketing instruments to achieve their corporate goals. For instance, according to Stanford Encyclopaedia of philosophy (2004), the Kantian perspective states that action based on free will is the only behaviour that is accepted as being good or ethical if it is taken for proper reason. Thus, Kant has concluded that other beautiful things associated with human beings, such as wealth, physical attributes, intelligence becomes bad and undesirable if they are used inappropriately, especially against the interest of the majority or for selfish purpose. Kant's argument is predicated to the principle of relating with others based on mutual respect without considering the beneficial values that such relationship will bring. In other words, people should not interact with each other primarily on the basis of exploiting such relationship for selfish purpose or as a means to selfish ends (Donaldson \& Werhane, 1999). According to Bowie (1998), this theory serves as the basis for considering the issues of moral obligation in human commercial exchanges, such as target marketing, which involves the mass media as legal entities, advertisers, women, and the public. Therefore, using Kant's argument, it is expected that all the parties involved in the web of target marketing should be accorded appropriate respect and dignity as human beings. However, looking at the current media contents, it may not be wrong to suggest that women who seem to play the central attraction in the scheme of exchange are not treated with respect and dignity. Therefore, considering the facts and applying the principle of Kant as explained above, one can conclude that the use of women sexually as marketing object in order to accomplish selfish aims by the media and advertisers is unethical.

Similarly, examining the issue from the utilitarian perspectives shows that the use of women as sexual object for marketing products and services is contrary to the ethical 
principle of producing the greatest goods for the happiness of the greatest number. This assumption is based on the fact that while mass media and advertisers can benefit from the exploitation of women, the majority of the public are left to face the consequences of their selfish act. For example, apart from its negative effect on the societal socialization process, sexual presentation of women and use of violent scenes by the media also affect the psychological dispositions of many gullible minds within the society. In addition, cultural values, family and spiritual orientations are equally affected. Considering the overall consequences, i.e. the use of women as marketing tools, that can have on the society, one may not be wrong to infer that instead of bringing the greatest happiness for the majority, this unfortunate act has continued to bring sadness, pains, and other social vices to the greatest number. The implication of this unfortunate development to human civilization will have probable consequences on the future generations unless it is properly addressed with immediate action.

A look at the issue from the Aristotelian perspective implies that the use of women as marketing objects can be examined from its ability to enhance their individual capacity to actualize their potentials in life. According to the Aristotelian principle, every person is born with the potentials of moral integrity, but that can only be actualized through appropriate socialization process from child hood to adult hood. Therefore, based on this assumption of Aristotelian's perspective, it can be concluded that human actions that are aimed at facilitating the achievement of these natural potentials are seen as good while those that constrain their actualizations are considered as bad except otherwise. Going by this argument, it is clear that although, women who are used as marketing tools get benefitted to some extent, many researchers have proved that most of these women who are known as 'models' have turn out to be drug addicts or lost their wills to actualize the dreams. In addition, such seductive appearances have contributed negatively in the socialization of children and youths in the society as some have shown to develop inappropriate sexual and violent habits early in life. In view of the above negative effects of exposing women as sexual object to the society, it is logical to conclude that the act is devoid of moral values; therefore, based on the Aristotelian principle, it is considered as unethical.

The perspective of business ethics is referred to applying ethical standards and principles, which underpin the function and regulation of marketing (Alshurideh et al., 2016). How organizations communicate ethically with their customers is a fundamental business issue nowadays because ethical communication is an important element in consumers' decision-making process and establishing a responsible relationship with them (Alshurideh et al., 2017). Marketing ethics are upheld by organizations that are socially responsible and employ ethical business practices (Becker-Olsen \& Guzmán, 2017). Similarly, in Islamic business ethics concept marketing communication about goods and services are not intentionally deceptive or misleading (Molla \& Alam, 2013). Additionally, in Islam, sellers and buyers are accountable to divine authority (God/ Allah); therefore, both should be honest and fair in their marketing activities (Alam et al., 2017). In the promotion of products, there should be no room to cover up promotional behaviour or hide any defect in the products (Abuznaid, 2012). In Islamic ethics, promotional techniques must not use sexual appeal, emotional appeal, fear appeal, false testimonies and pseudo research appeal, or contribute to the dullness of the mind or encourage extravagance. Within the Islamic framework, these methods are unethical since they are utilized purely to exploit the basic instinct of consumers worldwide with a view to gain profits and greater market share. Furthermore, Islamic ethics strictly prohibit stereotyping of women in advertising, and excessive use of fantasy. In 
addition, the use of suggestive language and behaviour and the use of women as objects to lure and attract customers are also not allowed in Islam (Hassan, Chachi \& Latiff, 2008).

Lastly, analysing this issue from the Contractarian principle consent of individual to abide by the rules and regulations of a group or political entity based on the recognition of the established authority shows that the majority of the population do not support the contents of the mass media. Consequently, the argument that the mass media has the right to use women for commercial advertisement does not enjoy the consent of the majority. Therefore, since the practice lacks the support and consent of the people, it should not be allowed to continue as a norm.

\section{Perspectives of Religious Ethics}

Religion is considered as the bindings of most ethical borders. Moreover, religion, as an element of culture, has a great effect on shaping the society, and it contributes to individuals' various decisions, including the buying decisions (Alam, Said \& Hassan, 2015; Hejase et al., 2012). Many religions are also very cautious about this matter (Kadić-Maglajlic' et al., 2014; Waller \& Fam, 2015; Fam et al., 2008), but Islam provides a very wide ethical guideline regarding this issue (Rafiki \& Abdul Wahab, 2014; Abbasi, Rehman \& Bibi, 2010; Asad, 2007). Islamic marketing ethics combines the principle of value maximization with the principles of equity and justice for the welfare of the society (Hassan, Chachi \& Latiff, 2008). Women occupy a unique and important place in Islam. They are various chapters in the holy Quran and Hadiths (documented deeds and sayings of the beloved prophet Muhammad (peace be upon Him- pbuh) that strongly emphasis on the issue of modesty and chastity among women.

To underscore the importance and relevance of women in the society, the holy Quran has a complete chapter (Surah $\mathrm{Al}$-Nisa) that deals with issues relating to women. In addition to this, Quran asserts that: "Tell the believing men to lower their gaze and (thus) guard their chastity. That is purer for them. Lo! God is aware of what they do. And tell the believing women to lower their gaze and (thus) guard their chastity ....and not to display of their adornment (zinah) except what (normally) becomes apparent thereof and to draw their headcoverings over their bosoms. [And also tell them] not to reveal any of their adornments save to their husbands or their fathers or their husbands' fathers, or their sons or their husbands' sons, or their brothers or their brothers' sons or their sisters' sons, or their womenfolk, or their slaves, or male attendants who lack vigour, or children as yet unaware of women's nakedness. And let them not stamp their feet so as to draw attention to what they hide of their charms. And turn unto God, O believers (both men and women), in order that you may prosper" (Quran, 24:30-31; see Ali, 1983). Quran also strongly warns not to propagate shameful things among the believers, "Verily those who love that indecency should spread among the believers deserve a painful chastisement in the world and in the Hereafter. Allah knows, but you do not know" (Quran, 24:19; see Ali, 1983).

In the similar manner, many Hadiths exist on the implications of women exposing their bodies and compromising their modesty and chastity in the society. For example, one Hadith mentioned that Prophet Mohammad (pbuh) said: "Allah has written for son of Adam (i.e. human being) his share of adultery which he inevitably commits. The adultery of the eye is looking (with desire), the adultery of the tongue is talking; the self wishes and desires and sexual organs then either testify all this (i.e., go along with the desire) or deny it" (Bukhari, 8(74): 260). Another Hadith mentioned that He (pbuh) said, "The whole world is a provision, 
and the best object of benefit of the world is the pious woman" (Muslim, 8:3465). Another Hadith mentioned that $\mathrm{He}$ (pbuh) also said, "Faith has over seventy branches, and modesty is a branch of faith" (Bukhari, 1(2):8; Muslim, 1:55).

Therefore, based on these strong injunctions from the Quran and Hadiths, several research findings have shown that the perception of sexual related advertisement messages among the Muslims are seen as offensive; as a result, the Muslim consider them as unethical.

Muslims consider women as the bedrock of child socialization in the family institution; therefore, they object to the ideas of exposing women as sexual marketing tools to their children. Apart from objecting to children being exposed to sexual oriented advertisement messages, Muslims are also conscious of the fact that Islam does not permit even adults (men and women) to watch nude pictures of each other unless they are in a legally sanctioned marital relationship. This is because exposure to nudity is also defined as adultery of the eye. For example, it is forbidden for Muslim men to look at women lustfully; thus, most Muslim men tent to avoid exposing themselves to sexual implied objects or images as they contain in most modern advertisement messages. Many Muslims believes that getting exposed to these nude advert messages leads to immoral behaviours, such as prostitution and adultery; the latter of them, i.e. adultery Quran categorically warns all Muslim believers to refrain from.

Although Islam recognizes freedom of choice by Muslims, it emphasises on the issue of rationality based on the Islamic principles of marketing, and the principles differ from the contemporary practices. For example, commercial exchanges or marketing in Islam is purely based on the comprehensive injunctions of the holy Quran, which strictly emphasises on the consideration of all moral issues as well as equity. For instance, Islamic marketing principle or ethics does not condone sales or advertisement of immoral or harmful products. This is the case with current sexual presentation of women by the mass media, false presentation of products to the potential consumers in order to attract their attention or induce them to buy by the use of sexual emotional images or languages and stereotyping of women, etc.

In view of the strong Islamic positions on the issue of marketing, it is apparent that the use of women as marketing tools in modern marketing, which is heavily embedded with seductive languages and images, is unethical.

\section{Implications and Recommendations}

Although modern marketing, particularly, organised advertisement and promotional activities can be a contentious exercise, issues relating to ethical standards may arise between the marketers and consumers; however, Lantos (1999) explained that producers of products/services could motivate their employees to adhere to the established ethical standards through the rule of corporate responsibility. For example, many corporate organizations are now creating formal links within their organizational structures in order to ensure that ethical issues are adhered to by their employees. Among the ethical issues are establishment of code of conducts, feedback by telephone lines for customers' complaints, community social responsibility committees, ethics and disciplinary committees, etc. In addition, ethical training programmes have aimed at enhancing awareness among employees on the importance of complying with ethical issues, such as consumers and public safety, morality, and other social problems are also undertaken. 
However, available literature shows that the issue of companies that engage in unethical presentation of women as sexual advertisement objects is not decreasing despite the existence of such ethical measures because of the congruence between nudity and effective advertisement (Severn \& Blech, 1990; Smith et al., 1995; Harker, 1998; Sherman \& Quester, 2005; Mathenge, 2013). Therefore, considering the various negative effects of target marketing with women as tools within the society, this paper takes the stand that the practice grossly falls short of human dignity and is offensive to acceptable moral and ethical principles and human dignity as argued by Mathenge (2013). In order to establish and maintain a balance between ethics and advertisement goals, the paper, therefore, recommends the followings:

Operating within the Limits of Social Responsibility Theory: Social responsibility theory is built on a system of ethics that stipulate that individuals, groups, and organizations must ethically validate their decisions and actions before proceeding. This implies that if the action or decision is taken or is to taken causes harm society or the environment, that would be deemed as socially irresponsible. Applying the relevant aspects of this theory to the issue of sexual presentation of women by advertisers means that advertising agencies should endeavour to operate within the limit stipulated by the theory instead of focusing on boosting sales in order to maximize profit.

Showing Respect for Human Dignity: The issue of human dignity in media ethics occupies a central position. Therefore, advertisement and marketing practitioners as an essential parts of the media family are expected to abide by this principle. Human dignity principle in media ethics states that advertisers cannot violate people's right "to make a responsible choice" or "exploit man's lower inclinations". Particularly, the relevant caveat is the concern for vulnerable groups, such as women, children, youth, elderly and poor people as well as the culturally disadvantaged (Foley, 1998) people. As such, advertisers should embrace a moral cosmos of non-hierarchical collective relationship and act ethically so as to honour human dignity ethically. In other words, advertising agencies should encourage their target audience to enjoy the fundamental need of human recognition and feel self-reflected in the advertising mirror.

Imposing Self-Regulatory System: Another way of reducing the unethical practices of making sexual implied advertisement is through self-regulation, more especially at the management level. This should be made a part of the management policy because irrespective of how the issue of ethics is communicated, there cannot be meaningful result unless the top level management endorses it. This policy should state clearly who is expected to follow them and which activities are acceptable as suggested by Fink (1988). Apart from being a reflection of advertising laws, self-regulation will help advertising agencies in avoiding deception and staying free from fraud, and this will further lead to the development of the advertising industry or profession (Drumwright, 2007).

Boycotting the Products or Services: In the event of advertising agencies' refusal to adopt any of the above suggestions, the public can resort to the principle of boycotting the products or services. This can be done through taking a collective position against the offensive media advertisement contents with women in sexually appealing postures. Once there is a collective position against the practice, the advertisers will be compelled to redress the issue because they need the market and would not want to lose it. 
These guidelines will help the business group, policy makers and also the consumers to be aware about the ethical issues related to the current practices that are going on in the marketing communication. Marketing managers should realize that having a greater understanding of the potential consumers, organizations will be more aware of the cultural and religious differences and take control of their social responsibility to produce more suitable market communication in any part of the world. Moreover, regarding the religious consumers, especially the Muslim communities, these recommendations can bring some substantial changes in the minds of the policy makers.

\section{Conclusion and Future Research}

Many research findings indicate that the contemporary global marketing revolves around the principle of "sex sells'; as a result, women have become the focal point in the hands of advertisers and mass media. Even though the practice has been attracting serious criticisms from the many people for contributing to moral decadence in the society, most advertisement messages have continued to contain images of women in semi-nude postures that reveal their physical and natural endowments as a way of suggesting or implying their sexual attractiveness. The spontaneous dissemination of such messages by the mass media for commercial gains without considering the public interest has almost become part of its agenda setting. Thus, because of its pervasiveness, many people, especially youths are now becoming obsessed with nudity as it seems to reflect in their ways of dressing, music, movies, and daily interactions. Furthermore, the exposure of people to these immoral advertisement images by the media on daily basis seems to portray those women who are presented in a sexually explicit posture as role models, particularly for the vulnerable youths.

The continuous dissemination of the messages by the mass media, therefore, raises some basic questions about the media and its clients (advertisers) to conform to ethical standards. For example, apart from their respective professional ethics, marketing ethics in general deals with moral standards, which every marketer is expected to adhere to, and they include taking both existing and potential customers interest as a factor during planning, production stages of goods/services and also giving good consideration to environmental, economic, and other social issues. Similarly, according to Islamic marketing principles, apart from ensuring equity among the parties involved in any transaction, it is also important that issues relating to harmful products/services or offensive to public sensitivities, such as inferior or adulterated products, false or deceitful presentation of products/service, display of offensive images, such as nudity of men and women, etc. should not be presented before the potential customers. This means that customers will not be deceived or directly coerced into surrendering their independent freedom of choice and decision; consequently, ethical issues must be taken as a component of marketing strategy.

Finally, this review study will open the door of conducting empirical study in future to get better view regarding gender issues, business, ethics, morality, and religion. This study will draw guidelines for identifying the factors, which could lead the secular world to modify their moral values and come closer to the norms of other civilized societies. Therefore, it might be interesting to conduct extensive quantitative studies examining the relationship among sexist advertisements and degradation of morality among youth generation. Additionally, the impacts need to be assessed empirically based on the different medium of communication, such as print, billboard, radio, television, etc. Moreover, determining the level of acceptability of nudity among different types of culture and different segments of people, including religious group, social group, children, would be another direction of 
research. Finally, it is very important to study the methods and application of censorship, monitoring and controlling the issue from the legal side as well as from consumer side.

\section{References}

Abbasi A.S., Rehman K, Bibi A. (2010). Islamic leadership model an accountability perspective. World Appl. Sci. J. 9(3): 230-238.

Abuznaid S. (2012). Islamic Marketing: Addressing the Muslim Market. An - Najah Univ. J. Res. (Humanities), 26(6): 1473-1503.

Alam, M.M., Akbar, C.S., Shahriar, S.M., \& Elahi, M.M. (2017). The Islamic Shariah Principles for Investment in Stock Market. Qualitative Research in Financial Markets, 9(2), 132-146.

Alam, M.M., Said, J., \& Hassan, S. (2015). Performance of Islamic Microcredit in Terms of Maqasid Al-Shariah: Case Study on Amanah Ikhtiar Malaysia. Humanomics, 31(4), 374-384.

Alexander, M. Wayne, and Jr. Ben Judd. "Do Nudes in Ads Enhance Brand Recall?.” Journal of Advertising Research 18 (1978): 47-50.

Ali, A. Yusuf. The Holy Quran: Text. Translation and Commentary. Maryland: Amana Corporation. $1983 . \quad$ Accessed January 2, 2014. http://www.islam101.com/quran/yusufAli/

Allen, Mike, Dave D'Allesio, and Keri Brezgel. "A Meta-Analysis Summarizing the Effects of Pornography. II: Aggression after Exposure.” Human Communication Research 22 (1995): 258-283.

Alshurideh, M., B. Al Kurdi, A. Abu Hussien, and H. Alshaar. (2017). "Determining the main factors affecting consumers' acceptance of ethical advertising: A review of the Jordanian market." Journal of Marketing Communications 23( 5), 513-532.

Alshurideh, M., B. Al Kurdi, A. Vij, Z. Obiedat, and A. Naser. 2016. "Marketing Ethics and Relationship Marketing-An Empirical Study that Measure the Effect of Ethics Practices Application on Maintaining Relationships with Customers." International Business Research 9 (9), 78-90.

Ameen, E., Guffey, D., and McMillan, J. (1996). Gender Differences in Determining the Ethical Sensitivity of Future Accounting Professionals, Journal of Business Ethics 15: 591-597.

Arlow, P. (1991). Personal Characteristics in College Students' Evaluations of Business Ethics and Corporate Social Responsibility, Journal of Business Ethics 10: 63-69.

Asad M. (2007). The principles of state and government in Islam, Islamic Book Trust, Kuala Lumpur.

Ashraf, C.A., Amin, S., \& Ahmad, M.I. (2015). "Presentation of women in sexual role influence by television and its entertainment programmes." Global Journal of Management and Social Science Research 3(1): 47-53.

Atkin, Charles, and Mark Miller, "The effects of television advertising on children: Experimental evidence" (paper presented at the meeting of the International Communication Association, Chicago, IL, April, 1975).

Baker, Christina N. "Images of Women's Sexuality in Advertisements: A Content Analysis of Black- and White-Oriented Women's and Men's Magazines.” Sex Roles 52 (2005): $13-27$.

Bandura, Albert. Social Learning Theory. Englewood Cliffs, NJ: Prentice-Hall, 1977.

Becker-Olsen, K., and F. Guzmán. 2017. "Corporate Social Responsibility Communication in North America: The past, Present and Future." In Handbook of Integrated CSR 
Communication, edited by S. Diehl, M. Karmasin, B. Mueller, R. Terlutter, and F. Weder, 293-315. Switzerland: Springer International Publishing.

Beckwith, Joan B. "Terminology and social relevance in psychological research on gender." Social Behavior and Personality 22 (1994): 329-336.

Bello, D. C., R. E. Pitts, and M. J. Etzel. 1983. "The Communication Effects of Controversial Sexual Content in Television Programs and Commercials." Journal of Advertising 12 (3), 32-42.

Beutel, A., and Marini, M. (1995). Gender and Values, American Sociological Review 60 (3): 436-448.

Boddewyn, J. \& Kunz, H. (1991). Sex and Decency Issues in Advertising: General and International Dimensions. Business Horizons, 34(5), pp. 13-20.

Bowie, Norman E. "A Kantian Theory of Capitalism.” Business Ethics Quarterly Special Issue no 1 (1998): 37-60.

Breines, Juliana G., Jennifer Crocker, and Julie A. Garcia. "Self-objectification and wellbeing in women's daily lives." Personality and Social Psychology Bulletin 34 (2008): 583598.

Brown, Jane D. "Mass Media Influences on Sexuality." The Journal of Sex Research 39 (2002): 42-45.

Bruce, J. (2015). Morality from the Classroom to the Boardroom: The Moral Foundations and Financial Risk Perceptions of Business Students, Conference Papers-American Sociological Association, pp. 1-32.

Bryła, P., \& Gruczyńska, A. (2018). The Perception of Sexually Provocative Advertisements of American Apparel by Generation Y in Poland. Polish Sociological Review, 201 (1), 109-125.

Bukhari. Accessed January 2, 2014. http://quranexplorer.com/Hadith/English/Index.html

Bushman, Brad J. "Violence and Sex in Television Programs Do Not Sell Products in Advertisements." Psychological Science 16 (2005): 702-708.

Bushman, Brad J., and Angelica M. Bonacci. "Violence and Sex Impair Memory for Television Ads." Journal of Applied Psychology 87 (2002): 557-564.

Cohen, J., Pant, L., and Sharp, D. (1998). The Effect of Gender and Academic Discipline Diversity on the Ethical Evaluations, Ethical Intentions, and Ethical Orientation of Potential Public Accounting Recruits, Accounting Horizons 12: 250-270.

Dahlen, M., \& Rosengren, S. (2016). If Advertising Won't Die, What Will It Be? Toward a Working Definition of Advertising. Journal Of Advertising, 45(3): 334-345.

Dawson, L. (1997). Ethical Differences between Men and Women in the Sales World, Journal of Business Ethics 16: 1143-1152.

Donaldson, Thomas, and Patricia H. Werhane. Ethical Issues in Business: A Philosophical Approach. Englewood Cliffs, N.J: Prentice-Hall, 1999.

Drumwright, M. E. "Advertising Ethics: A Multi-Level Approach" In G. J. Tellis and T. Ambler (Eds.) The Sage Handbook of Advertising (pp. 17-34). Los Angeles, CA: SAGE Publications, 2007.

Emmers, Tara, Mike Allen, and Lisa Gebhardt. "Exposure to Pornography and Acceptance of the Rape Myths." Journal of Communication 45 (1995): 5-26.

Fam, K-S., Waller, D.S., Ong, F.S. and Yang, Z. (2008) 'Controversial product advertising in China: perceptions of three generational cohorts', Journal of Consumer Behaviour, 7 (6), 461-469.

Fink, C. C. Media Ethics in the Newsroom and Beyond. New York: McGraw-Hill, 1988.

Foley, J.P. "Ethics in Advertising: A Look at the Report by the Pontifical Council for Social Communications." Journal of Public Policy and Marketing 17 (2) (1998): 313-315. 
Ford, T., Boxer, C., Armstrong, J., \& Edel, J. (2007). More Than "Just a Joke": The Prejudice-Releasing Function of Sexist Humor. Personality And Social Psychology Bulletin, 34(2): 159-170.

Fredrickson Barbara L., and Tomi-Ann Roberts. "Objectification theory: Toward understanding women's lived experiences and mental health risks." Psychology of Women Quarterly 21 (1997): 173-206.

Goffman, E. (1979). Gender Advertisements (1st ed.). London: Macmillan.

Greene, Beverly. "African American women." In Woman of color: Integrating ethnic and gender identities in psychotherapy. ed. Lillian Comas-Diaz and Beverly Greene. New York: Guilford, 1994.

Groza, N., \& Cuesta, J. (2011). Sexist Humour in Advertising: Just a Joke or Marketing Strategy?. International Journal Of Arts And Technology, 4(1): 61-73.

Harker, D. (2008). Regulating Online Advertising: The Benefit of Qualitative Insights. Qualitative Market Research: An International Journal, 11(3), pp. 295-315.

Harker, D. "Achieving acceptable advertising." International marketing review 15 (1998): 101-118.

Harper, Brit, and Marika Tiggemann. "The effect of thin ideal media images on women's self-objectification, mood, and body image." Sex Roles (2008): 649-657.

Hassan, A., Chachi, A \& Latiff S.A. (2008). Islamic Marketing Ethics and Its Impact on Customer Satisfaction in the Islamic Banking Industry. JKAU: Islamic Economics, 21(1): 27-46.

Hejase, H., Hamdar, H., Orfali, O., Hejase, H. (2012). Marketing Mix: An Exploratory Research in Syria from an Islamic Perspective. American J. of Scientific Res., 82: 3352.

Huang, Y., \& Lowry, D. (2011). An Analysis of Nudity in Chinese Magazine Advertising: Examining Gender, Racial and Brand Differences. Sex Roles, 66(7-8): 440-452.

Jones, S., \& Reid, A. (2011). Sex and Sexism in Australian Alcohol Advertising: (Why) Are Women More Offended than Men?. Contemporary Management Research, 7(3): 211230.

Kadić-Maglajlić, S., Arslanagić-Kalajdžić, M., Micevski, M., Michaelidou, N. and Nemkova, E., 2017. Controversial Advert Perceptions in SNS Advertising: The Role of Ethical Judgement and Religious Commitment. Journal of business ethics, 141(2), pp.249265.

Lambiase, J., \& Reichert, T., (2003). How to Get "Kissably Close": Examining How Advertisers Appeal to Consumers' Sexual Needs and Desires. Sexuality And Culture, 7(3): 120-136.

Lambiase, Jacqueliene, and Tom Reichert. Sex in Advertising. Mahwah, New Jersey: Lawrence Erlbaum Associates, 2003.

Lanis, Kyra, and Katherine Covell. "Images of Women in Advertisements: Effects on Attitudes Related to Sexual Aggression." Sex Roles 32 (1995): 639-649.

Lantos, Geoffrey P. "Motivating moral corporate behavior". Journal of Consumer Marketing 16(3) (1999): $222-233$.

Latour, M., \& Henthorne, T. (1994). Ethical Judgments of Sexual Appeals in Print Advertising. Journal Of Advertising, 23(3): 81-90.

Lee, H., Harrell, G., \& Droge, C. (2000). Product Experiences and Hierarchy of Advertising Effects. AMA Winter Educators' Conference, 11, eds. John P. Workman and William D. Perreault (Chicago: American Marketing Association, 2000), pp. 41 - 42.

Levy, J. (2008). Advertising to Women. Journal Of Creativity In Mental Health, 2(4): 75- 86.

Liu, F., H. Cheng, and J. Li. 2009. "Consumer Responses to Sex Appeal Advertising: A Cross-cultural Study.” International Marketing Review 26 (4-5), 501-520. 
Mathenge, G. D. "Ethical Issues in Advertising and Marketing: An Empirical Analysis of the Hindrances to Efficient Marketing and Product Communication Management in Kenya." European Journal of Business and Innovation Research 1(4) (2013): 9-19.

Mercurio, Andrea E., and Laura J. Landry. "Self-objectification and well-being: The impact of self-objectification on women's overall sense of self-worth and life satisfaction." Sex Roles 58 (2008): 458-466.

Milakovic, I., \& Mihic, M. (2015). Predictors and Outcome of Attitudes Towards Advertising: Demographics, Personal Factors and WOM. Ekonomska Misao $i$ Prakska; Dubrovnik, 24(2): 409-432.

Molla, R.I., \& Alam, M.M. (2013). A Third Sector-Led Economic Model: Scopes for Islamic Entrepreneurship. American Journal of Islamic Social Sciences, 30(1), 73-91.

Moradi, Bonnie, and Yu-Ping Huang. "Objectification theory and psychology of women: A decade of advances and future directions." Psychology of Women Quarterly 32 (2008): 277-398.

Muslim. Accessed January 2, 2014. http://quranexplorer.com/Hadith/English/Index.html

Ogechukwu, A. D., A. K. Ndubueze, and A. V. Uche. 2011. "Ethical Issues Involved in Integrated Marketing Communication in Nigeria." Business Management Dynamics 1 (4), 50-62.

O'Guinn, T., Allen, C., \& Semenik, R. (2009). Advertising and Integrated Brand Promotion (5th ed.). London: Cengage Learning.

Orth, U. \& Holancova, D. (2003). Consumer Response to Sex Role Portrayals in Advertising: Effects of Incongruity and Prejudices on Emotions and Attitudes. Journal of Advertising, 32(4): 77-89.

Parry, S., Jones, R., Stern, P. and Robinson, M. (2013) “"Shockvertising”: an exploratory investigation into attitudinal variations and emotional reactions to shock advertising', Journal of Consumer Behaviour, 12(2), 112-121.

Paul, Richard, and Elder Linda. The miniature Guide to Understanding the Foundations of Ethical Reasoning. Tomales, CA: Foundation for Critical Thinking Press, 2006.

Peterson, R., Beltramini, R., and Kozmetsky, G. (1991). Concerns of College Students Regarding Business Ethics: A Replication, Journal of Business Ethics 10 (10): 733738.

Pingree, S., Hawkins, R., Butler, M., \& Paisley, W. (1976). A Scale for Sexism. Journal of Communication, 26(4): 193-200.

Pope, N., Voges, K., \& Brown, M. (2004). The Effect of Provocation in the Form of Mild Erotica on Attitude to the Ad and Corporate Image: Differences Between CauseRelated and Product-Based Advertising. Journal Of Advertising, 33(1): 69-82.

Pradhan, D., Duraipandian, I., \& Sethi, D. (2014). Celebrity Endorsement: How CelebrityBrand-User Personality Congruence Affects Brand Attitude and Purchase Intention. Journal Of Marketing Communications, 22(5): 456-473.

Putrevu, S. and Swimberghek, K. (2013) 'The influence of religiosity on consumer ethical judgments and responses toward sexual appeals', Journal of business ethics, 115(2), 351-365.

Rafiki A, Abdul Wahab, K. (2014). Islamic Values and Principles in the Organization: A Review of Literature. Asian Social Sci. 10(9), 1-7.

RAINN. "Who are the Victims?" and "How often does sexual assault occur?". Accessed January 2, 2014. http://www.rainn.org/get-information/statistics/sexual-assaultvictims.

Reichert, T., S. E. Heckler, and S. Jackson. (2001). "The Effects of Sexual Social Marketing Appeals on Cognitive Processing and Persuasion." Journal of Advertising 30 (1), 1327. 
Reichert, Tom, Susan E. Heckler, and Sally Jackson. "The Effects of Sexual Social Marketing Appeals on Cognitive Processing and Persuasion." Journal of Advertising 30(1) (2001), 13-27.

Reid, L. N., and L. C. Soley. (1981). "Another Look at the "Decorative" Female Model: The Recognition of Visual and Verbal Ad Components." Current Issues and Research in Advertising 4 (1), 123-133.

Reid, L. N., and L. C. Soley. (1983). "Decorative Models and the Readership of Magazine Ads." Journal of Advertising Research 23 (2), 27-32.

Richmond, David, and Timothy P. Hartman. "Sex Appeal in Advertising." Journal of Advertising Research 22 (1982): 53-61.

Root, Maria P. P. "The psychology of Asian women." In Bringing cultural diversity to feminist psychology: Theory, research, practice. ed. H. Landrine. Washington, DC: American Psychological Association,1995.

Rouner, D., Slater, M., \& Domenech-Rodríguez, M. (2003). Adolescent Evaluation of Gender Role and Sexual Imagery in Television Advertisements. Journal of Broadcasting \& Electronic Media, 47(3): 435-454.

Ryan, Michelle K., and Barbara David. "Gender Differences in Ways of Knowing: The Context Dependence on Attitudes toward Thinking and Learning Survey." Sex Roles 49(11/12) (2003): 693-99.

Schiffman, L., Wisenblit, J., \& Kanuk, L. (2010). Consumer Behavior (10th ed). Boston: Pearson.

Severn, J., and G. E. Belch. "The effects of sexual and non-sexual advertising appeals and information level on cognitive processing and communication effectiveness." Journal of Advertising 19 (1) (1990): 14-22.

Sherman, C. \& Quester, P. (2005). The Influence of Product/Nudity Congruence on Advertising Effectiveness. Journal Of Promotion Management, 11(2-3): 61-89.

Sherman, C. and Pascale Quester. "The Influence of Product/Nudity Congruence on Advertising Effectiveness." Journal of Promotion Management 11(2/3) (2005): 6189.

Smith, S. M., C. P. Haugtvedt, J. M. Jadrich, and M. R. Anton. "Understanding responses to sex appeals in advertising: An individual difference approach." Advances in Consumer Research 22(1995):735-39.

Steadman, Major. "How Sexy Illustrations Affect Brand Recall." Journal of Advertising 9 (1969): 15-19.

Stern, Steven E., and Alysia D. Handel. "Sexuality and Mass Media: The Historical Context of Psychology's Reaction to Sexuality on the Internet." The Journal of Sex Research 38 (2001): 283-291.

Strasburger, Victor C., and Barbara J. Wilson. Children, Adolescents, \& the Media. Thousand Oaks, CA: Sage Publications, 2002.

Taflinger, Richard F. "Taking Advantage: You and Me, Babe: Sex and Advertising." 1996. Accessed January 2, 2014. http://www.wsu.edu:8080/ taflinge/sex.html.

Taylor, K., Miyazaki, A. \& Mogensen, K. (2013). Sex, Beauty, and Youth: An Analysis of Advertising Appeals Targeting U.S. Women of Different Age Groups. Journal of Current Issues \& Research in Advertising, 34(2): 212-228.

The National Campaign. "About The National Campaign." Accessed January 2, 2014. http://www.thenationalcampaign.org/about-us/default.aspx

Thiyagarajan, S., P. Shanthi, and G. Naresh. 2012. "Viewers' Perception of TV Ads: The Role of Sex Appeal." Psychology Research 2 (8), 452-460.

Ting, H. and De Run, E.C. (2012). 'Generations X and Y attitude towards controversial advertising', Asian Journal of Business Research, 2 (2),24-37. 
Treise, D., M. Weigold, J. Conna, and H. Garrison. (1994). "Ethics in Advertising: Ideological Correlates of Consumer Perceptions." Journal of Advertising 23 (3), 5969.

Van Zoonen, Liesbet. Feminist Media Studies. Thousand Oaks: Sage, 1994.

Vezich, I., Gunter, B. and Lieberman, M. (2017). Women's Responses to Stereotypical Media Portrayals: An fMRI Study of Sexualized and Domestic Images of Women. Journal of Consumer Behaviour, 16(4): 322-331.

Waller, D.S. (2007) 'Reasons for offence towards the advertising of gender-related products', Journal of Consumer Satisfaction/Dissatisfaction \& Complaint Behavior, 20, 72-85.

Waller, D.S., and Fam, K.S. (2015). "Attitudes towards sexual images in Chinese advertisements by religion." International Journal of Chinese Culture and Management 3 (4): 413-425.

Waller, David S. "Attitudes towards offensive advertising." Journal of consumer marketing 16 (1999): 288-294.

Yoon, H.J. (2013). Understanding schema incongruity as a process in advertising: Review and future recommendations, Journal of Marketing Communications, 19(5): 360-376.

Zell, E., Strickhouser, J., Lane, T., \& Teeter, S. (2016). Mars, Venus, or Earth? Sexism and the Exaggeration of Psychological Gender Differences. Sex Roles, 75(7-8): 287-300.

Zillmann, Dolf. "Influence of Unrestrained Access to Erotica on Adolescents' and Young Adults' Dispositions and Toward Sexuality." Journal of Adolescent Health 27 (2) (2000): 41-44. 